\title{
A Comparison of Physical Education Students' Motivation Using Polish and Turkish Versions of the Academic Motivation Scale
}

\author{
by \\ Agnieszka Ardeńska1, Rajmund Tomik, Serkan Berber², Burak Düz ${ }^{3}$, Barış Çivak ${ }^{3}$, \\ Ŭ̆ur Çalişkan ${ }^{4}$, Joanna Ogrodnik
}

Motivation is an important phenomenon in the realm of education, particularly in the university fields connected with physical education and sport, where it is necessary to accommodate and balance intellectual abilities and physical fitness. The present study tested motivation levels among university students in the fields connected with physical education and sport in Poland and Turkey. It was based on the Self-Determination Theory (Deci and Ryan, 1985), namely intrinsic motivation, extrinsic motivation and amotivation which impact human behaviour. The Academic Motivation Scale was used (Vallerand et al., 1992). The aims of the study were twofold, first, to crossculturally validate Polish and Turkish versions of the Academic Motivation Scale and second, to identify and compare the motivation to study depending on nationality and gender. Both Polish and Turkish versions of the questionnaire were validated and converted to a four-factorial structure. The findings indicated that Polish and Turkish students' motivation especially differed in amotivation and intrinsic motivation to know and experience stimulation. Moreover, Turkish female students proved to be at the lowest estimate of amotivation.

Key words: intrinsic motivation, extrinsic motivation, physical education and sport.

\section{Introduction}

Motivation is the driving force behind undertaking any actions. Intrinsic motivation might be the key to accomplishing goals in the area of education, especially in physical education, which merges intellectual and physical development. Supporting, inspiring and initiating intrinsic motivation are the desirable tasks of physical educators, like PE teachers, coaches, personal trainers etc., considering all levels and aspects of physical education. Physical education teachers can influence students' selfdetermination, and ipso facto enhance or undermine intrinsic motivation, through the applied motivational strategies (Taylor, 2008). It is of great importance not to undermine existing intrinsic motivation, particularly at the lowest levels of physical education, in elementary or grammar schools. People who are intrinsically motivated to physical exercises will be physically active throughout their lives. Intrinsic motivation to experience stimulation is a strong predictor of intention to be physically active after graduation from school (Hein, 2004).

The current cross-cultural analysis and comparison of the university students' motivation in the area of physical education, prospective PE teachers and coaches was based on the SelfDetermination Theory by Deci and Ryan (1985). Human behaviour relies on the realization of innate needs for autonomy, competence and

\footnotetext{
1 - Faculty of Physical Education, The Jerzy Kukuczka Academy of Physical Education in Katowice, Poland.

2 - Faculty of Sport Sciences, Anadolu University, Eskişehir, Turkey.

3 - Tourism Faculty, Anadolu University, Eskişehir, Turkey

4 - Faculty of Tourism, Muğla Sıtkı Koçman University, Turkey.
} 
relationships that constitute foundations of all kinds of motivation (Deci and Ryan, 1985; Deci et al., 1991; Vallerand, 2000). Basic psychological needs are of great importance for motivation in education, both for students and teachers, as well as for administrators and politicians who reform educational structures. Deci (2009) notes: Successful school reform requires that administrators, teachers, and students internalize the value of improved teaching and learning and of the policies, structures, procedures, and behaviors implicit in the reform. This is most likely to happen when school personnel and students experience satisfaction of their basic psychological needs for autonomy, competence, and relatedness while planning and implementing the reform.

Motivation could form a continuum from amotivation through controlled extrinsic motivation, to autonomic intrinsic motivation due to the transformation in the process of internalisation. There are two types of internalization, i.e. introjection which refers to internalization in which one assumes a value, although does not identify with it, and integration, when the person identifies with the value of an activity and fully accepts it (Deci et al., 1994). Van den Berghe et al. (2014) noticed: The logic behind internalization and autonomous motivation is attractive for the practice of physical education. Ryan and Deci $(2000 \mathrm{a}, 2000 \mathrm{~b})$ proposed a taxonomy of human motivation relying on amotivation and four levels of extrinsic motivation in the following order: external regulation, introjection, identification, integration and intrinsic motivation. Amotivation is a state in which a person does not feel the need to undertake an activity and does not feel competent to perform it (Deci, 1975). It is also a state of lacking the intention to act and results from not valuing an activity (Ryan and Deci, 2000b). Additionally, an individual does not believe that undertaking an activity will allow him/her to achieve desired goals and does not see any relationship between the activity and its effect and therefore believes that the behaviour as well as the activity is caused by factors beyond one's control (Deci and Ryan, 1985; Vallerand et al., 1992). Extrinsic motivation pertains to an activity which is performed in order to attain some specific outcome. Extrinsic motivation can vary greatly considering the degree to which it is autonomous. The least internalized and autonomous is external regulation when human behaviour is controlled by external contingencies, and one acts to attain a desired consequence such as tangible rewards or to avoid a threatened punishment. Introjected regulation, identified regulation and finally integration, are progressively more internalized and autonomous. An integrated regulation is the most complete and internalized form of extrinsic motivation (Deci and Ryan, 2000; Ryan and Deci, 2000a). Intrinsic motivation, fully autonomous, refers to performing an activity simply for the enjoyment of the activity itself. Intrinsic motivation contributes to high-quality learning and creativity, thus it is especially important to identify the factors and forces that engender or undermine it (Ryan and Deci, 2000a). Intrinsic motivation, as a fully autonomous phenomenon, can be undermined by external rewards, which tend to forestall self-regulation. People undermine taking responsibility for motivating and regulating themselves, so tangible rewards induce a negative effect on intrinsic motivation (Deci et al., 1999). The evolving theory of selfdetermination allows to constantly improve our understanding of the processes taking place in the human psyche during a variety of activities (education, sport-related or recreational physical activity, etc.) and, in the end, also allows to improve physical fitness (Deci and Ryan, 2008; Vallerand et al., 2008).

Vallerand et al. (1992) created the Academic Motivation Scale based on a seven factor subscale motivation structure: amotivation, three types of extrinsic motivation (external, introjected and identified regulation) and three types of intrinsic motivation (intrinsic motivation to know, to accomplish things and to experience stimulation). Extrinsic motivation is divided into external regulations, connected with rewards and punishments, external introjected motivation accepted in the processes of internalization by introjection and external identified motivation accepted following internalization by identification, which an individual considers his or her own and which is the closest to intrinsic motivation. Intrinsic motivation pertains to practicing an activity for itself, just for pleasure and satisfaction (Deci, 1975; Deci and Ryan, 1985; Vallerand, 1992). 
The objectives of the study were twofold, first, to validate the Academic Motivation Scale to Polish and Turkish versions, and second, to compare motivation to study in the fields connected with physical education in Polish and Turkish university students. We hypothesized that there would be a significant difference in motivation to study between Polish and Turkish students as well as in motivation depending on gender and nationality of the surveyed.

\section{Material and Methods}

\section{Participants and measures}

In the present study, the Academic Motivation Scale (AMS) was used. The questionnaire was completed between 2013 and 2015 by Polish and Turkish university students of physical education, coaching, recreation and sport. Participation in the study was voluntary and anonymous. The sample selection was purposeful. A total of 406 questionnaires were collected, of which 219 were completed by Polish (130 males and 89 females) and 186 by Turkish (145 males and 41 females) students. The AMS items were translated in accordance with the forward- and back-translation procedure from English to Polish and from English to Turkish. The original AMS comprises seven subscales of four items each, assessing three types of intrinsic motivation (to know, toward accomplishments, to experience stimulation), three types of extrinsic motivation (external regulation, introjected regulation, identified regulation) and one type of amotivation. Altogether it consists of 28 items graded from 1 to 7 in the Likert-type scale (1 definitely no, 2 - no, 3 - rather no, 4 - I don't know, 5 - yes, 7 - definitely yes). The surveyed referred to the subsequent points assessing to what extent the statements were consistent with the reasons for which they studied.

\section{Statistical analysis}

All statistical analyses were performed with STATISTICA 12 software. The factor analysis was used to validate the AMS due to its translation from English to Polish and from English to Turkish as well as cross-cultural differences. Furthermore, an exploratory factor analysis (EFA) and a confirmatory factor analysis (CFA) were conducted to validate a seven-factor model of the AMS in both Polish and Turkish versions. The Kaiser criterion and the Cattel's scree plot were used to determine the optimal number of factors during the EFA. The principal components (PC) method of the extraction was used to estimate factor loadings and unique variances of the model. Factor loadings had undergone the Varimax rotation. To estimate the unknown variables of the generalized model, the least-squares method was used during the CFA. Internal consistency was measured with Cronbach alpha. Factor analyses were carried out separately for Polish and Turkish versions in the following order: exploratory for 28 factors according to 28 items of the scale, exploratory and confirmatory for seven factors according to the seven-factor structure of the original AMS, exploratory and confirmatory for five-factor, and finally for the four-factor structure. The four-factor model was used to compare motivation of Polish and Turkish students, both male and female. Descriptive statistics were calculated for each of the four levels of motivation. In order to validate the hypotheses, the non-parametric Mann-Whitney U test (significance of motivation differences in Polish and Turkish students) and Kruskal Walis test by ranks along with post-hoc multiple comparisons tests (significance of motivation differences both in nationality and gender) were applied. The assumed significance level was set at $\alpha<0.05$.

\section{Results}

The Polish version of the AMS was tested first. An exploratory factor analysis for 28 factors (28 questionnaire items) was performed. Due to the Kaiser criterion, the eigenvalues for the correlation matrix were computed. The eigenvalues of six factors were greater than 1.00 and they explained $64.42 \%$ of total variance. Five factors explained $60.78 \%$ and four factors explained $56.65 \%$ of total variance. The highest eigenvalue for the first factor was 8.94. The eigenvalue for the seventh factor was below 1.00 (.85). Through examining the Cattel's scree plot from the fourth factor, the last substantial drop in the magnitude of eigenvalues could be determined, although the six factors' eigenvalues were under or equal to 1.00 . Next, assuming a seven-factor structure with 28 items, exploratory factor analysis was performed. Factor loadings did not confirm the existence of seven factors, subscales of motivation. Next, the data was 
subjected to a confirmatory factor analysis. The seven-factor and 28 items model yielded fit values $\left(\chi^{2}=706.13 ; \mathrm{df}=350 ; p<.001 ; \mathrm{GFI}=.79 ; \mathrm{AGFI}=\right.$ .75) lower than the ones reported by Vallerand (1992) before adding correlated 26 residuals $\left(\chi^{2}=\right.$ 1228.27; $\mathrm{df}=329 ; p<.001 ; \mathrm{GFI}=.89 ;$ AGFI $=.87$ ). Ten variables (items of questionnaire) of the seven-factor model including all four items of intrinsic motivation to know were statistically non-significant $(p>.05)$. The procedure was reiterated for five-factor and four-factor models. After all, the evaluation of the four-factor 21-item model variables (Table 1) was satisfactory. All variables were significant $(p<.05)$. Four factors corresponded to new four subscales of motivation denominated: amotivation (AM), extrinsic motivation regulated and partly identified (EREID), extrinsic motivation internalized and toward accomplishments (EINIMA), intrinsic motivation to know and to experience stimulation (IMKES).

The internal consistency of the four-factor 21-item model was measured using Cronbach alpha. Cronbach $\alpha$ values (above .78 total amotivation and motivation; .88 extrinsic and intrinsic motivation; .83 amotivation $\mathrm{AM}$; .84 extrinsic motivation EREID; .85 extrinsic-intrinsic motivation EINIMA; .82 intrinsic motivation IMKES) in all cases above .78 were obtained. The outcome of the analysis provided evidence of high, internally consistent reliability of the chosen four-factor model.

A similar procedure in the Turkish version of the questionnaire was performed. An exploratory factor analysis for 28 factors was executed. Based on the Kaiser criterion, the eigenvalues for the correlation matrix were computed. The eigenvalues of five factors were greater than 1.00 and they explained $64.98 \%$ of total variance. Four factors explained $61.33 \%$ of total variance. The highest eigenvalue for the first factor was 10.10. The sixth and the seventh factor eigenvalues were below $1.00(.91 ; .88)$. Examining the Cattell's scree plot, the last substantial drop in the magnitude of eigenvalues could be determined from the fourth factor, although five factors' eigenvalues were above or equal to 1.00. Next, assuming seven-factor structure with 28 items, exploratory factor analysis was carried out. Factor loadings did not confirm the existence of seven factors, subscales of motivation. The data was then subjected to a confirmatory factor analysis. The seven-factor and 28 items model yielded fit values $\left(\chi^{2}=554.23 ; \mathrm{df}=350 ; p<.001\right.$; GFI $=.79$; AGFI $=.75$ ) lower than the ones reported by Vallerand $(1992)\left(\chi^{2}=1228.27 ; \mathrm{df}=\right.$ 329; $p<.001$; GFI = .89; AGFI = .87). Five-factor and four-factor models were tested. Ultimately, the evaluation of four-factor 22-item model variables (Table 2) was satisfactory. All variables were significant $(p<.05)$. Four factors corresponded to the new four subscales of motivation denominated as in the Polish version: amotivation (AM), extrinsic motivation regulated and partly identified (EREID), extrinsic motivation internalized and toward accomplishments (EINIMA), intrinsic motivation to know and to experience stimulation (IMKES).

The internal consistency of the four-factor 22-item model was calculated using Cronbach alpha. The obtained Cronbach $\alpha$ values (.82 total amotivation and motivation; .89 extrinsic and intrinsic motivation; .85 amotivation $\mathrm{AM}$; .79 extrinsic motivation EREID; .83 extrinsic-intrinsic motivation EINIMA; 89 intrinsic motivation IMKES) were above .79 in all subscales. The outcome of the analysis provided evidence of high, internally consistent reliability of the fourfactor model.

After two four-factor models (Polish 21 items and Turkish 22 items) were postulated in order to assess whether arithmetic means would be a reliable measure, skewness and kurtosis were calculated separately for both samples (Polish students $n=219$, Turkish students $n=186$ ). The values for kurtosis (Polish range from -1.06 to .50; Turkish range from -.30 to 0.80 , and 2.57 for EREID, with mean 5,65, median 5,83, dominant 6,50 ) and skewness (Polish range from -.82 to 1.27; Turkish range from -1.40 to 1.30 ) were satisfactory. The arithmetic means (M) and standard deviations (SD) for subscales were calculated. In order to validate the hypotheses, the non-parametric Mann-Whitney $U$ test (significance of motivation differences for Polish and Turkish students) and Kruskal Wallis test along with post-hoc multiple comparisons tests (significance of motivation differences for nationality and gender) were applied.

The highest mean (Table 3) was obtained in extrinsic motivation regulated and partly identified (EREID) in both Polish (5.24) and 
Turkish (5.65) students, although the mean value of Turkish students was significantly higher. A significantly $(p<.05)$ higher mean in the subscale of intrinsic motivation to know and to experience stimulation (IMKES) was observed in Turkish students (4.85) compared to Polish students (3.95).
Polish students were more amotivated (2.78) than Turkish students (2.20) and the difference was statistically significant $(p<.05)$. No significant differences between Polish and Turkish students were observed in the extrinsic motivation internalized and toward accomplishments subscale (EINIMA).

\begin{tabular}{|c|c|c|c|c|}
\hline \multirow{2}{*}{\multicolumn{5}{|c|}{ CFA, Polish version of the four-factor 21-item model }} \\
\hline & & & & \\
\hline Items & Value & SD & $\mathbf{T}$ & $p$ \\
\hline \multicolumn{5}{|l|}{ Factor: Amotivation } \\
\hline $\begin{array}{l}\text { AM5. Honestly, I don't know; I really feel that I am wasting my time in } \\
\text { school. }\end{array}$ & 0.69 & 0.11 & 6.10 & .00 \\
\hline $\begin{array}{l}\text { AM12. I once had good reasons for going to university; however, now I } \\
\text { wonder whether I should continue. }\end{array}$ & 0.68 & 0.12 & 5.50 & .00 \\
\hline AM19. I can't see why I go to university and frankly, I couldn't care less. & 1.01 & 0.12 & 8.39 & .00 \\
\hline AM26. I don't know; I can't understand what I am doing in school. & 1.18 & 0.11 & 1.86 & .00 \\
\hline \multicolumn{5}{|l|}{ Factor: Extrinsic motivation regulated and partly identified } \\
\hline ER8. In order to obtain a more prestigious job later on. & 0.74 & 0.11 & 6.91 & .00 \\
\hline ER15. Because I want to have "the good life" later on. & 0.51 & 0.10 & 4.98 & .00 \\
\hline ER22. In order to have a better salary later on. & 0.84 & 0.11 & 7.77 & .00 \\
\hline $\begin{array}{l}\text { EID10. Because eventually it will enable me to enter the job market in a field } \\
\text { that I like. }\end{array}$ & 0.57 & 0.11 & 5.12 & .00 \\
\hline $\begin{array}{l}\text { EID17. Because this will help me make a better choice regarding my career } \\
\text { orientation. }\end{array}$ & 0.49 & 0.10 & 5.03 & .00 \\
\hline \multicolumn{5}{|l|}{ Factor: Extrinsic motivation internalized to accomplishments } \\
\hline $\begin{array}{l}\text { EIN7. To prove to myself that I am capable of completing my university } \\
\text { degree. }\end{array}$ & 0.55 & 0.12 & 4.66 & .00 \\
\hline EIN14. Because of the fact that when I succeed in university I feel important. & 0.92 & 0.11 & 8.09 & .00 \\
\hline EIN21. To show myself that I am an intelligent person. & 0.78 & 0.13 & 6.08 & .00 \\
\hline EIN28. Because I want to show myself that I can succeed in my studies. & 0.79 & 0.11 & 7.04 & .00 \\
\hline $\begin{array}{l}\text { IMA13. For the pleasure that I experience while I am surpassing myself in one } \\
\text { of my personal accomplishments. }\end{array}$ & 0.53 & 0.10 & 5.36 & .00 \\
\hline $\begin{array}{l}\text { IMA20. For the satisfaction I feel when I am in the process of accomplishing } \\
\text { difficult academic activities. }\end{array}$ & 0.70 & 0.10 & 7.00 & .00 \\
\hline \multicolumn{5}{|l|}{ Factor: Intrinsic motivation to know and to experience stimulation } \\
\hline $\begin{array}{l}\text { IES4. For the intense feelings I experience when I am communicating my own } \\
\text { ideas to others. }\end{array}$ & 0.41 & 0.12 & 3.39 & .00 \\
\hline IES11. For the pleasure that I experience when I read interesting authors. & 0.85 & 0.12 & 7.36 & .00 \\
\hline $\begin{array}{l}\text { IES18. For the pleasure that I experience when I feel completely absorbed by } \\
\text { what certain authors have written. }\end{array}$ & 0.56 & 0.10 & 5.38 & .00 \\
\hline $\begin{array}{l}\text { IES25. For the "high" feeling that I experience while reading about various } \\
\text { interesting subjects. }\end{array}$ & 0.75 & 0.12 & 6.20 & .00 \\
\hline $\begin{array}{l}\text { IMK2. Because I experience pleasure and satisfaction while learning new } \\
\text { things. }\end{array}$ & 0.32 & 0.11 & 2.82 & .00 \\
\hline $\begin{array}{l}\text { IMK9. For the pleasure I experience when I discover new things never seen } \\
\text { before. }\end{array}$ & 0.27 & 0.11 & 2.41 & .02 \\
\hline
\end{tabular}


Table 2

CFA, Turkish version of the four-factor 22-item model

\begin{tabular}{lcccc}
\hline \multicolumn{1}{c}{ Items } & Value & SD & T & $p$ \\
\hline \multicolumn{1}{c}{ Factor: Amotivation } & & & & \\
\hline $\begin{array}{l}\text { AM5. Honestly, I don't know; I really feel that I am wasting my time in } \\
\text { school. }\end{array}$ & 0.84 & 0.12 & 6.85 & .00 \\
$\begin{array}{l}\text { AM12. I once had good reasons for going to university; however, now I } \\
\text { wonder whether I should continue. }\end{array}$ & 0.85 & 0.14 & 6.06 & .00 \\
$\begin{array}{l}\text { AM19. I can't see why I go to university and frankly, I couldn't care less. } \\
\text { AM26. I don't know; I can't understand what I am doing in school. }\end{array}$ & 0.89 & 0.12 & 7.29 & .00 \\
\hline
\end{tabular}

Factor: Extrinsic motivation regulated and partly identified

ER1. Because with only a high-school degree I would not find a highpaying job later on.

ER8. In order to obtain a more prestigious job later on.

\begin{tabular}{llll}
0.76 & 0.18 & 4.22 & .00 \\
0.67 & 0.10 & 6.80 & .00 \\
0.50 & 0.08 & 6.08 & .00 \\
1.08 & 0.12 & 9.30 & .00 \\
0.31 & 0.11 & 2.79 & .01 \\
0.59 & 0.09 & 6.41 & .00 \\
\hline
\end{tabular}

ER15. Because I want to have "the good life" later on.

ER22. In order to have a better salary later on.

EID10. Because eventually it will enable me to enter the job market in a field that I like.

EID17. Because this will help me make a better choice regarding my career orientation.

Factor: Extrinsic motivation internalized to accomplishments

EIN7. To prove to myself that I am capable of completing my university degree.

\begin{tabular}{llll}
0.54 & 0.17 & 3.17 & .00 \\
0.94 & 0.15 & 6.17 & .00 \\
0.88 & 0.14 & 6.42 & .00 \\
0.46 & 0.12 & 3.69 & .00 \\
0.90 & 0.13 & 7.22 & .00 \\
\hline
\end{tabular}

EIN21. To show myself that I am an intelligent person.

EIN28. Because I want to show myself that I can succeed in my studies.

IMA20. For the satisfaction I feel when I am in the process of accomplishing difficult academic activities.

IMA27. Because university allows me to experience a personal satisfaction in my quest for excellence in my studies.

mulation

\begin{tabular}{|c|c|c|c|c|}
\hline $\begin{array}{l}\text { IES4. For the intense feelings I experience when I am communicating my } \\
\text { own ideas to others. }\end{array}$ & 0.66 & 0.14 & 4.71 & .00 \\
\hline IES11. For the pleasure that I experience when I read interesting authors. & 1.08 & 0.13 & 8.47 & .00 \\
\hline $\begin{array}{l}\text { IES18. For the pleasure that I experience when I feel completely absorbed by } \\
\text { what certain authors have written. }\end{array}$ & 1.18 & 0.12 & 9.58 & .00 \\
\hline $\begin{array}{l}\text { IES25. For the "high" feeling that I experience while reading about various } \\
\text { interesting subjects. }\end{array}$ & 0.72 & 0.11 & 6.79 & .00 \\
\hline $\begin{array}{l}\text { IMK9. For the pleasure I experience when I discover new things never seen } \\
\text { before. }\end{array}$ & 0.45 & 0.11 & 4.23 & .00 \\
\hline $\begin{array}{l}\text { IMK16. For the pleasure that I experience in broadening my knowledge } \\
\text { about subjects which appeal to me. }\end{array}$ & 0.23 & 0.10 & 2.26 & .02 \\
\hline $\begin{array}{l}\text { IMK23. Because my studies allow me to continue to learn about many } \\
\text { things that interest me. }\end{array}$ & 0.28 & 0.10 & 2.73 & .01 \\
\hline
\end{tabular}


Table 3

Means, standard deviations and significance of differences

\begin{tabular}{|c|c|c|c|c|c|}
\hline \multicolumn{6}{|c|}{ Mann Whitney's U significance test } \\
\hline \multirow[t]{2}{*}{ Factor (subscale of motivation) } & \multicolumn{2}{|c|}{$\begin{array}{c}\text { Polish } \\
\text { students } n=219\end{array}$} & \multicolumn{2}{|c|}{$\begin{array}{l}\text { Turkish students } \\
\mathrm{n}=186\end{array}$} & \multirow{2}{*}{$p$} \\
\hline & Mean & SD & Mean & SD & \\
\hline Amotivation (AM) & 2.78 & 1.44 & 2.20 & 1.46 & .00 \\
\hline $\begin{array}{l}\text { Extrinsic motivation regulated and partly identified } \\
\text { (EREID) }\end{array}$ & 5.24 & 1.17 & 5.65 & 1.11 & .00 \\
\hline $\begin{array}{l}\text { Extrinsic motivation internalized and toward } \\
\text { accomplishments (EINIMA) }\end{array}$ & 4.42 & 1.28 & 4.33 & 1.49 & .54 \\
\hline $\begin{array}{l}\text { Intrinsic motivation to know and to experience stimulation } \\
\text { (IMKES) }\end{array}$ & 3.95 & 1.09 & 4.82 & 1.33 & .00 \\
\hline
\end{tabular}

\begin{tabular}{|c|c|c|c|c|c|}
\hline \multicolumn{6}{|c|}{ Kruskal Wallis and post-hoc tests } \\
\hline \multirow{2}{*}{ Factor (subscale) } & \multirow{2}{*}{\multicolumn{2}{|c|}{ Gender }} & Polish & Turkish & \multirow{2}{*}{$p$} \\
\hline & & & $\mathrm{M}(\mathrm{SD})$ & $\mathrm{M}(\mathrm{SD})$ & \\
\hline \multirow{3}{*}{ Amotivation (AM) } & Male & & $2.84(1.49)$ & $2.36(1.54)$ & .01 \\
\hline & Female & & $2.71(1.38)$ & $1.62(.95)$ & .00 \\
\hline & $p$ & $.07^{*}$ & 1.00 & .02 & $.00^{* *}$ \\
\hline \multirow{3}{*}{$\begin{array}{l}\text { Extrinsic motivation regulated and } \\
\text { partly identified (EREID) }\end{array}$} & Male & & $5.17(1.22)$ & $5.59(1.17)$ & .00 \\
\hline & Female & & $5.35(1.09)$ & $5.87(.83)$ & .07 \\
\hline & $p$ & $.23^{*}$ & 1.00 & 1.00 & $.00^{* *}$ \\
\hline \multirow{3}{*}{$\begin{array}{l}\text { Extrinsic motivation internalized } \\
\text { and toward accomplishments } \\
\text { (EINIMA) }\end{array}$} & Male & & $4.20(1.33)$ & $4.26(1.51)$ & 1.00 \\
\hline & Female & & $4.73(1.13)$ & $4.58(1.42)$ & 1.00 \\
\hline & $p$ & $.09^{*}$ & .04 & 1.00 & $.95^{* *}$ \\
\hline \multirow{3}{*}{$\begin{array}{l}\text { Intrinsic motivation to know and to } \\
\text { experience stimulation (IMKES) }\end{array}$} & Male & & $3.91(1.11)$ & $4.73(1.40)$ & .00 \\
\hline & Female & & $4.00(1.06)$ & $5.11(1.05)$ & .00 \\
\hline & $p$ & $.00^{*}$ & 1.00 & .67 & $.00^{* *}$ \\
\hline
\end{tabular}

* diagonally situated $p$-values for Polish female $(n=89)$ and Turkish male $(n=145)$ students

** diagonally situated $p$-values for Polish male $(n=130)$ and Turkish female $(n=41)$ students

Furthermore, mean values of subscales of motivation depending on the nationality and gender of students were compared. The highest mean value was observed in Polish male (2.84) and female (2.71) students for the amotivation subscale with $p$-value equal to 1.00 . The lowest mean value for amotivation was found in Turkish female students (1.62) and it was statistically significant $(\underline{p}<.01)$. Also statistically significant differences in mean values were noticed for the extrinsic motivation partly identified subscale. The difference concerned the highest mean value for Turkish female students (5.87) and the lowest mean for Polish male students (5.17). This lowest mean was significantly different compared to the mean value for Turkish male students (5.59). The highest mean value of the extrinsic motivation internalized and toward accomplishments 
subscale was found for Polish female students (4.73) and it was significantly different compared to Polish male students (4.20). The results revealed most statistically significant differences in intrinsic motivation to know and to experience stimulation. The Turkish female students presented the highest mean value (5.11) for that subscale, that was significantly different from the average for Polish female (4.00) and male (3.91) students. Both averages for Polish students were significantly lower compared to Turkish male students (4.73).

\section{Discussion}

In the present study, following explanatory and confirmatory factor analyses performed independently for the Polish and Turkish versions of the Academic Motivation Scale, four factors corresponding to subscales of motivation were found instead of the seven factors of the original AMS by Vallerand et al. (1992). One subscale, amotivation, was maintained as original. The items of intrinsic motivation to know and to experience stimulation were created of the subscale of intrinsic motivation. The most untypical to the posited selfdetermination continuum were two subscales of extrinsic motivation. One of them, called extrinsic motivation regulated and partly identified, was created with items of external and identified regulation. The second one, named extrinsic motivation introjected and to accomplishments, consisted of items of introjected regulation and intrinsic motivation toward accomplishments.

\section{Validation}

Similarly, a four-factor structure was found in the German adaptation of the AMS by Wilkesmann et al. (2012) with a sample of 3687 university students, although the AMS was reduced to 21 items and a 5 point Likert scale was used instead of a 7 point one. Karagüven (2012) suggested a five factor structure in the adaptation of the AMS to Turkish, with a sample of 390 university students. Three factors suggested by Karagüven i.e. amotivation, intrinsic motivation and introjected motivation and to accomplish, were similar to Polish-Turkish presented research. The factor called amotivation contained all original items of amotivation, as in the current research. The factor which Karagüven called introjected regulation and to accomplish connecting items of extrinsic introjected regulation and toward accomplishments was similar to the factor in the current research as well. The third of the similar factors was intrinsic motivation (Karagüven, 2012). In previous research untypical correlations between subscales of the extrinsic motivation and intrinsic motivation to accomplishments were also found. Data from a subsample of 915 from a total sample of 1406 college students from an east-coast US university were used by Fairchild et al. (2005) to re-examine a seven-factor model of the AMS. Contrary to the self-determination continuum, the intrinsic motivation to accomplishments correlated more positively with introjected regulation (.78) than with identified regulation (.51) and the identified regulation correlated more positively with extrinsic regulation (.71) rather than with the introjected regulation (.48).

Barkoukis and colleagues (2008) validated the Greek version of the AMS in Study 1 and Study 2. In Study 1 (911 students) four models were tested: a 7-factor uncorrelated measurement model, a 7-factor correlated measurement model, a 5-factor correlated model and a 2-factor hierarchical model. In Study 2 (303 students) intrinsic motivation to accomplish correlated more positively (.60) with introjected regulation than with identified regulation (.42). In turn identified regulation was most positively correlated with external regulation (.68), and intrinsic motivation to know and intrinsic motivation to experience stimulation were correlated positively with the coefficient equal to .66 (Barkoukis et al., 2008). These subscales were united in pairs in the present research and named extrinsic motivation introjected and toward accomplishments, external regulation partly identified and intrinsic motivation to know and to experience stimulation. Ratelle et al. (2007) used the AMS comparing Study 1 (4,498 high school students), Study 2 (942 high school students) and Study 3 (410 college students) and posited a five-factor structure, with amotivation, external regulation, introjected regulation, identified regulation and intrinsic motivation. In Study 1 there was a substantial correlation (.74) between intrinsic motivation and introjected regulation, higher than the correlation between intrinsic motivation and identified regulation (.53), and the correlation between identified regulation and extrinsic regulation (.49) was higher compared to the 
correlation between introjected and extrinsic regulation (.31). In Study 2, as in Study 1, there was a high positive correlation between introjected regulation and intrinsic motivation (.60), the correlation between identified and extrinsic regulation (.47) was nearly equivalent to the correlation between introjected and extrinsic regulation (.44). Correlation analyses in Study 3 (college) were more in line with the selfdetermination theory compared to Studies 1 and 2 (high school). The reason of these correlations, so untypical of research in self-determination theory, could be the prevalence of constraints and rewards in high school (Ratelle et al., 2007). In the present study, similar and untypical selfdetermination continuum connections concerned Polish and Turkish university students of physical education. Guay et al. (2014) tested the AMS by comparing results of the Confirmatory Factor Analysis and Exploratory Structural Equation Modelling in Study 1 (French-Canadian 1416 college students) and Study 2 (French-language Canadian 4498 high school students) obtained from a CFA similar correlation. Intrinsic motivation to accomplish correlated more positively (.69 in Study 1 and .89 in Study 2) with introjected (internalized) regulation than with identified regulation (.65 in Study 1 and .63 in Study 2).

Lepper et al. (2005) noticed that: it may be quite adaptive for students to seek activities that they find inherently pleasurable while simultaneously paying attention to the extrinsic consequences of those activities in any specific context. Focusing only on pleasure with no attention to external constraints may reduce future outcomes and opportunities. Contrarily, attending only to extrinsic constraints can undermine the enjoyment that can come from learning itself (Lepper et al., 2005).

The four-factor structure led to classified motivation and divided into amotivation, extrinsic motivation partly identified, extrinsic motivation introjected and to accomplishments, intrinsic motivation to know and to experience stimulation. That structure suggested a heterogeneous nature of the extrinsic motivation, connected with the complicated process of internalization. It could be compared to a taxonomy of human motivation posited by Deci and Ryan (2000a, 2000b) and one of Deci and Ryan' subtheories, called organismic integration theory (Deci and Ryan, 1985), introduced to detail the different forms of extrinsic motivation and the contextual factors promoting or hindering internalization and integration (Ryan and Deci, 2000a).

\section{Amotivation}

Analyzing the motivational profiles depending on nationality, Turkish students were less amotivated compared to their Polish counterparts. Considering gender, the comparison revealed Turkish female students to be the group with the lowest level of amotivation, significantly different from others. Furthermore, there were no significant differences between Polish female and male students regarding amotivation. Significantly lower amotivation among female students was observed in the research conducted in French-language Canada (Vallerand et al., 1992), in Greece (Barkoulis et al., 2008), in the United States (Horyna and Bonds-Raake, 2012), in Turkish second grade colleges (Turkmen, 2013), in French-Canadian colleges and high schools (Guay et al., 2014). Thus, Polish female university students of physical education seem to be an exception.

\section{Extrinsic motivation}

Although the highest means were obtained for the subscale of extrinsic motivation regulated and partly identified both for Turkish and Polish students, they were significantly higher for Turks. Similarly, the highest mean for the extrinsic motivation was observed by Hegarty (2010) while testing motivation of 240 business and educational courses university students in the northeast United States. Also Vallarand and coworkers (1992) obtained the highest mean for the extrinsic motivation, identified regulation for females and external regulation for males, validating the Academic Motivation Scale questionnaire by testing 745 university students, after it was translated from French to English.

The statistically significant difference was found in the highest mean value for Turkish female students and the lowest mean for Polish male students for the extrinsic motivation partly identified subscale. Polish female students achieved the highest mean value of the extrinsic motivation introjected and toward accomplishments subscale, which was significantly different compared to Polish male students. Horyna and Bonds-Raacke (2012), while 
studying the motivation of 283 students of psychology courses, found significant differences in the higher mean of external regulation and extrinsic identified motivation for females. Wilkessmann and co-workers (2012) observed lower extrinsic motivation among women, when testing 3687 students from three universities in Germany.

\section{Intrinsic motivation}

We found that Turkish students were significantly more intrinsically motivated compared to their Polish counterparts. In our study, Turkish students constituted a more varied sample as they were students of physical education, coaching, recreation and sport, while Polish students formed a more homogeneous group, all studying physical education. The strength of intrinsic motivation can be specific for a field of a study. A significant difference in intrinsic motivation between students in the two fields of study, business (lower mean) and education (higher mean) was observed by Hegarty (2010). The strength of intrinsic motivation depends on basic psychological needs of autonomy, competence and relatedness, but first of all, it depends on autonomy, and, in the areas of widely understood education, intrinsic motivation can be supported or undermined by the teacher. Klain et al. (2015) studied the influence of autonomy support induced by the physical educator on the motivational regulation in subjects attending fitness academies as well as following personal training and its impact on adherence to exercise. Comparison of 405 subjects who performed physical exercise in fitness academies and 183 who followed personal training showed that subjects following personal training were more self-determined and more involved in physical exercise. Gender differences on the subscale of intrinsic motivation to know and to experience stimulation were not observed. The differences between Polish and Turkish students of both genders were probably caused by nationality differences. In previous investigations, female students proved to be more intrinsically motivated. Vallarand et al. (1992) obtained significant differences in motivation of women and men in all the intrinsic motivation subscales. In the Greek version of the AMS, based on a sample of 911 high school students, the analyses revealed significant gender differences in the subscale of the intrinsic motivation to know, where females showed higher mean values than males (Barkoukis et al., 2008). On the other hand, males were more intrinsically motivated in the study of 240 ten-pin bowlers in Malaysia (EngWah et al., 2015). However, the research was not strictly related to university education, but to widely understood physical education and sport.

\section{Conclusions and limitation}

The results of the present study showed that Turkish students were less amotivated and more intrinsically motivated compared to Polish students. The research confirmed the strength of the items of amotivation and the intrinsic motivation to experience stimulation subscales. Several observed trends were connected with internalization of extrinsic motivation. Although, it should be highlighted that presented results are restricted to Polish and Turkish university students of physical education and sport. The research should be replicated with the modified questionnaires and new samples to verify the four-factor structure of the AMS. The present comparison of the Polish and Turkish students' motivation was based on untypical subscales compared to the original AMS. Therefore, conclusions should be limited to three or two dimensions (amotivation, extrinsic motivation, intrinsic motivation or amotivation and intrinsic motivation) before iterating research. The main limitation of the study consisted of the heterogeneous Turkish (students of physical education, coaching, recreation, sport) and homogeneous Polish samples (physical education only).

\section{References}

Barkoukis V, Tsorbatzoudis H, Grouios G, Sideridis G. The Assessment of Intrinsic and Extrinsic Motivation and Amotivation: Validity and Reliability of the Greek Version of the Academic Motivation Scale. Assessment in Education: Principles, Policy \& Practice, 2008; 15(1): 39-55 
Deci EL, Eghrari H, Patrick BC, Leone DR. Facilitating: The Self-Determination Theory Perspective. Journal of Personality, 1994; 62(1): 119-142

Deci EL, Koestner R, Ryan RM. A Meta-Analytic Review of Experiments Examining the Effects of Extrinsic Rewards on Intrinsic Motivation. Psychological Bulletin, 1999; 125: 627-668

Deci EL, Ryan RM. Intrinsic Motivation and Self-Determination in Human Behavior. New York: Plenum Press; 1985

Deci EL, Ryan RM. The "what" and "why" of Goal Pursuits: Human Needs and the Self-Determination of Behavior. Psychological Inquiry, 2000; 11: 227-68

Deci EL, Ryan RM. Self-Determination Theory: A Macrotheory of Human Motivation, Development, and Health. Canadian Psychology, 2008; 49(3): 182-185

Deci EL, Vallerand RJ, Pelletier LG, Ryan RM. Motivation and Education: The Self-Determination Perspective. Educational Psychologist, 1991; 26(3,4): 325-346

Deci EL. Intrinsic Motivation. New York: Plenum Press; 1975

Deci EL. Large-Scale School Reform as Viewed from the Self-Determination Theory Perspective. Theory and Research in Education, 2009; 7: 244-252

Eng-Wah T, Khoo S, Wong R, Eng-Hoe W, Boon-Hooi L, Rengasamy SS. Intrinsic and Extrinsic Motivation Among Adolescent Ten-Pin Bowlers in Kuala Lumpur, Malaysia. Journal of Human Kinetics, 2015; 45: $241-251$

Fairchild AJ, Horst SJ, Finney SJ, Barron KE. Evaluating Existing and New Validity Evidence for the Academic Motivation Scale. Contemporary Educational Psychology, 2005; 30(3): 331-358

Guay F, Morin AJS, Litalien D, Valois P, Vallerand RJ. Application of Exploratory Structural Equation Modeling to Evaluate the Academic Motivation Scale. The Journal of Experimental Education, 2015; 83(1): $1-32$

Hegarty N. Application of the Academic Motivation Scale to Graduate School Students. The Journal of Human Resource and Adult Learning, 2010; 6(2): 48-55

Hein V, Müür M, Koka A. Intention to Be Physically Active after School Graduation and Its Relationship to Three Types of Intrinsic Motivation. European Physical Education Review, 2004; 10(1): 5-19

Horyna B, Bonds-Raacke JM. Differences in Students' Motivation to Attend College: Large versus Small High Schools. Education, 2012; 132(4): 708-724

Karagüven MHÜ. The Adaptation of Academic Motivation Scale of Turkish. Educational Sciences: Theory $\mathcal{E}$ Practice, 2012; 12(4): 2611-2618

Klain IP, Gama de Matos D, Leitão JC, Cid L, Moutão J. Self-Determination and Physical Exercise Adherence in the Contexts of Fitness Academies and Personal Training. Journal of Human Kinetics, 2015; 46: 241249

Lepper, MR, Corpus JH, Iyengar SS. Intrinsic and extrinsic motivational orientations in the classroom: Age differences and academic correlates. Journal of Educational Psychology, 2005; 97: 184-196

Ratelle CF, Guay F, Vallerand RJ, Larose S, Senecal C. Autonomous, Controlled, and Amotivated Types of Academic Motivation: A Person-Oriented Analysis. Journal of Educational Psychology, 2007; 99: 734-746

Ryan RM, Deci EL. Self-Determination Theory and the Facilitation of Intrinsic Motivation, Social Development and Well-Being. American Psychologist, 2000a; 55(1): 68-87

Ryan RM, Deci EL. Intrinsic and Extrinsic Motivations: Classic Definitions and New Directions. Contemporary Educational Psychology, 2000b; 25: 54-67

Taylor IM, Ntoumanis N, Standage M. A Self-Determination Theory Approach to Understanding the Antecedents of Teachers' Motivational Strategies in Physical Education. Journal of Sport \& Exercise Psychology, 2008; 3: 75-94

Turkmen M. The Relationships between Gender, Physical Self-Perception, Sport Experience, Motivation Orientations and Academic Success. International Journal of Academic Research, 2013; 5(5): 66-72

Vallerand RJ, Pelletier LG, Blais MR, Brière NM, Senecal C, Vallieres EF. The Academic Motivation Scale: A Measure of Intrinsic, Extrinsic, and Amotivation in Education. Educational and Psychological

(C) Editorial Committee of Journal of Human Kinetics 
Measurement, 1992; 52: 1003-1017

Vallerand RJ, Pelletier LG, Koestner R. Reflections on Self-Determination Theory. Canadian Psychology, 2008; 49(3): 257-262

Vallerand RJ. Deci and Ryan's Self-Determination Theory: A View from the Hierarchical Model of Intrinsic and Extrinsic Motivation. Psychological Inquiry, 2000; 11(4): 312-318

Van den Berghe L, Vansteenkiste M, Cardon G, Kirk D, Haerens L. Research on self-determination in physical education: key findings and proposals for future research. Physical Education and Sport Pedagogy, 2014; 19(1): 97-121

Wilkesmann U, Fischer H, Virgillito A. Academic Motivation of Students - the German Case. Discussion papers des Zentrums für HochschulBildung, Technische Universität, Dortmund, 2012; 2: 1-19

\section{Corresponding author:}

\section{Agnieszka Ardeńska}

Faculty of Physical Education,

The Jerzy Kukuczka Academy of Physical Education in Katowice, Poland

Mikołowska 72a, 40-065 Katowice, Poland

Fax number: +48322075345

Phone number: 696446311

E-mail: a.ardenska@awf.katowice.pl 